\title{
Nutritional components of the sea cucumber Holothuria scabra
}

\author{
Morakot Sroyraya $^{1,2}$, Peter J. Hanna ${ }^{1,3}$, Tanapan Siangcham ${ }^{1,4}$, Ruchanok Tinikul', \\ Prapaporn Jattujan', Tanate Poomtong ${ }^{5}$, and Prasert Sobhon ${ }^{1,4} *$
}

${ }^{1}$ Department of Anatomy, Faculty of Science, Mahidol University, Bangkok 10400, Thailand. ${ }^{2}$ Mahidol University, Nakhonsawan Campus, Nakhonsawan 60130, Thailand. ${ }^{3}$ Pro ViceChancellor's Office, Faculty of Science and Technology, Deakin University, Locked Bag 2000, Geelong, Victoria 3220, Australia. ${ }^{4}$ Faculty of Allied Health Sciences, Burapha University, Bangsaen,Chonburi 20131, Thailand . ${ }^{5}$ Coastal Fisheries Research and Development Center, Klongwan, Prachuabkirikhan 77000, Thailand

*Corresponding author: Prasert Sobhon, $\mathrm{PhD}$, Professor, Department of Anatomy, Faculty of Science, Mahidol University, Rama 6 Road, Bangkok 10400, Thailand

Submission Date: September 21 ${ }^{\text {st }}, 2016$, Acceptance date: March $20^{\text {th }}, 2017$ : Publication date: March $31^{\text {st }}, 2017$

Citation: Sroyraya M., Hanna P.J., Siangcham T., Tinikul R., Jattujan P., Poomtong T., Sobhon P. Nutritional components of the sea cucumber Holothuria scabra. Functional Foods in Health and Disease 2017; 7(3): 168-181

\section{ABSTRACT}

Background: Holothuria scabra is one of the most commercially important species found in the Pacific region. The sea cucumber extracts have been widely reported to have beneficial health effects. The aim of this study was to determine the nutritional compositions of $H$. scabra, and compare its important nutritional contents with that of other species.

Methods: The sea cucumbers were dissected, sliced into small pieces, and then freeze-dried. The nutritional compositions, including proximate composition, amino acids, fatty acids, collagen, GABA, Vitamin A, C, and E of the whole body and body wall of $H$. scabra, were analyzed.

Results: $H$. scabra contained a high quantity of protein $(22.50 \%$ in whole body and $55.18 \%$ in body wall) and very low lipids (1.55\% in whole body and $1.02 \%$ in body wall). The three most abundant amino acids found in both the whole body and body wall were glycine, glutamic acid, and proline. The main fatty acids found in the whole body were stearic acid and nervonic acid, and in the body wall were arachidonic acid and stearic acid. The whole body and body wall also contained high levels of essential amino acids, essential fatty acids, and collagen, in addition to moderate amounts of vitamin $\mathrm{E}$ and low amounts of GABA and vitamin $\mathrm{C}$. 
Conclusions: The sea cucumber, H. scabra, contained high quantity of protein and very low lipid. It contained high essential amino acids, essential fatty acids, nervonic and arachidonic acids, and collagen, which also contained GABA, vitamin C, and vitamin E.

Keywords: sea cucumber; Holothuria scabra; nutrition components; functional food

\section{INTRODUCTION}

In China, sea cucumbers are one of the more popular health foods, as they are delicious and contain high levels of nutritional components [1]. In China, the sea cucumber or Apostichopus japanicus is the sole species of scaled aquaculture that is the most popular in the market [2]. In particular, they have been reported to contain a significant amount of high protein and low amount of fat [3]. They have been used in traditional medication to relieve pain and to heal internal and external wounds [4]. Sea cucumber extracts from various species exhibit tissue repair and wound healing capabilities $[5,6]$. Water-soluble extracts from the sea cucumber Stichopus hermanii incorporated into hydrogel enhances wound contraction and improves the histological reorganization of the regenerating tissue [6]. Moreover, sea cucumbers contain high amount of bioactive compounds such as peptides, polyunsaturated fatty acids [4], triterpene glycosides [7], and chondroitin sulfates [8]. Numerous studies have reported that sea cucumber extracts have the abilities to cure asthma [1], have cytotoxic property [7], and are also anticancer [7], anti-inflammatory [9], and antioxidant [10].

The sandfish, Holothuria scabra, is found mostly in the tropic areas of the Pacific region and is one of the most commercially important species [11]. However, there is little published nutritional information on this species. Thus, the purpose of our study was to determine the nutritional composition, including proximate composition, amino acid profile, fatty acid profile, collagen content, gamma aminobutyric acid (GABA) content, vitamin $\mathrm{A}, \mathrm{C}$, and $\mathrm{E}$ in the whole body and body wall; we then compared important nutritional contents found in this species to other species.

\section{MATERIALS AND METHODS}

\section{Sample preparation}

Sea cucumber, H. scabra, size $300 \pm 50 \mathrm{~g}(\mathrm{n}=4)$ were obtained from the Coastal Fisheries Research and Development Center in Prachuap Khirikhan Province, Thailand. The sea cucumbers were dissected and three samples collected, namely from the whole body (including, body wall, intestine, respiratory tree, nervous system, and gonad), body wall, and viscera (internal organs). All samples were sliced into small pieces and then freeze-dried before further preparations and analysis at the Central Laboratory Co., Ltd., Thailand.

\section{Proximate composition}

The proximate compositions of the whole body and body wall were analyzed for moisture content by oven-drying according to the AOAC method 950.46 [11]. In brief, the samples were air-dried in an oven at $100^{\circ}-102^{\circ} \mathrm{C}$ for $16-18 \mathrm{~h}$ then cooled in a desiccator and weighed. Lossin-weight was reported as moisture content. 
Crude protein was measured by the Kjeldahl (block digestion) method followed by AOAC method 981.10 [11]. Each dried sea cucumber sample was ground and weighed. Nitrogen in the sample was digested into ammonium sulfate by $\mathrm{H}_{2} \mathrm{SO}_{4}$, a catalyst tablet, and $30-35 \% \mathrm{H}_{2} \mathrm{O}_{2}$, in a block digestor at $410^{\circ} \mathrm{C}$ for $45 \mathrm{~min}$, until the solution was clear. Ammonium sulfate solution was then converted into ammonia by adding $\mathrm{NaOH}-\mathrm{Na}_{2} \mathrm{~S}_{2} \mathrm{O}_{3}$ solution, followed by the distillation of ammonia in $25 \mathrm{~mL} \mathrm{H}_{3} \mathrm{BO}_{3}$. The amount of ammonia was quantified by titration with $0.2 \mathrm{M} \mathrm{HCl}$ until reaching an end point.

Lipid was determined by an acid hydrolysis method according to the AOAC method 922.06 [11]. Briefly, lipid was extracted from each sample using $\mathrm{HCl}$ at $70-80^{\circ} \mathrm{C}$ for $30-40 \mathrm{~min}$ and then transferred to a Mojonnier fat-extraction apparatus. Redistilled petroleum ether was added to the extraction apparatus, the mixture shaken vigorously, and then left to stand until the upper liquid was practically clear. Ether-fat solution was filtered, evaporated, and then the samples were dried and weighed.

Ash content was determined by mineralization of samples according to the AOAC 920.153 [11]. The organic matter of the sea cucumber sample was removed by heating overnight in a muffle furnace at $550^{\circ} \mathrm{C}$. The residue of inorganic matter or ash was then weighed.

Carbohydrate was calculated by the following formula: Weight of carbohydrate $=$ Total dry weight - (weight of moisture + weight of crude protein + weight of lipid + weight of ash)

\section{Amino acid composition}

The total and free amino acid compositions of the sea cucumber whole body and body wall were analyzed by reversed-phase HPLC. For the total amino acid analysis, sea cucumber samples were ground and passed through a 40 mesh sieve. The samples were hydrolyzed under nitrogen with $6 \mathrm{M} \mathrm{HCl}$. To avoid the loss of sulphur containing amino acids, i.e. cysteine and methionine, each sample was oxidized by performic acid prior to $\mathrm{HCl}$ hydrolysis at $110{ }^{\circ} \mathrm{C}$ for $24 \mathrm{~h}$. The amino acids were derivatized with phenylisothiocyanate into isothiocyanate derivatives and then analyzed by reversed-phase HPLC. Individual amino acids were identified and quantified by comparison with retention times and peak areas of standard amino acids.

For free amino acid determinations, sea cucumber samples were mixed with $0.5 \%$ trifluoroacetic acid in methanol and centrifuged at $3000 \times \mathrm{g}$ for $5 \mathrm{~min}$. Free amino acids in the samples were then converted into phenyl isothiocyanate derivatives, and analyzed by reversedphase HPLC as described previously.

\section{Fatty acid composition}

Fatty acid compositions of the sea cucumber whole body and body wall were analyzed by gas chromatography with a flame ionization detector (GC-FID), according to the AOAC method 996.06 [12]. In brief, each sea cucumber sample was weighed, mixed with an internal standard (TAG 13:0 and TAG 11:0), and then hydrolyzed with $\mathrm{HCl}$. The fat was extracted with ethyl ether and petroleum ether. The ether extract was filtered, dried, and methylated into fatty acid methyl ester (FAME). The FAME of each sample was determined by GC-FID and each fatty acid identified and quantified by comparison with retention times and peak areas of FAME against the internal standard. 


\section{Collagen content}

The collagen of sea cucumber whole body and body wall were determined using a hydroxyproline assay, according to the AOAC method 990.26 [12]. Each sample was ground, weighed, and hydrolyzed in $\mathrm{H}_{2} \mathrm{SO}_{4}$ at $105^{\circ} \mathrm{C}$ for $16 \mathrm{~h}$. The solution was diluted to $500 \mathrm{~mL}$ with distilled water. Part of the solution was filtered and then the filtrate was diluted to make a final concentration of hydroxyproline in range $0.5-2.4 \mu \mathrm{g} / \mathrm{mL}$ ( $5 \mathrm{~mL}$ filtrate $+95 \mathrm{~mL}$ distilled water). Hyproxyproline was oxidized to pyrrole, mixed with color reagent (4dimethyllamiobenzaldehyde $10 \mathrm{~g}$ in $35 \mathrm{~mL}$ perchloric acid and $65 \mathrm{~mL}$ 2-propanol), and incubated in a water bath at $60^{\circ} \mathrm{C}$ for $15 \mathrm{~min}$. The optical density of the solution and blanks was measured at $558 \mathrm{~nm}$ with a spectrophotometer. The hydroxyproline standard with varying concentrations were used to plot a standard curve. The conversion factor for calculating the collagen contents from hydroxyproline was 8 .

\section{Gamma aminobutyric acid (GABA) content}

The GABA contents of the sea cucumber whole body and body wall were determined by gas chromatography-mass spectrometry (GC-MS). The samples were prepared according to Iwaki and Kitada [13]. In short, the freeze-dried samples were ground into powder and homogenized separately with $25 \mathrm{~mL}$ of $75 \%$ ethanol in a homogenizer. Each homogenate was filtered through filter paper with pore size 5-10 $\mu \mathrm{m}$. The residues were then extracted 3 times with $25 \mathrm{~m} \mathrm{~L}$ of $75 \%$ ethanol and the volume of filtrate was made up with $75 \%$ ethanol to $100 \mathrm{~mL}$. The samples were analyzed by GC-MS and the GABA contents were determined and quantified by comparison with retention times and peak areas of an internal standard.

\section{Vitamin A (retinol) and vitamin E ( $\alpha$-tocopherol)}

Vitamin A and E contents in the sea cucumber whole body and body wall were analyzed, according to an in-house method based on a liquid chromatographic analysis of food and beverage [14]. Briefly, dried samples were ground, passed through a 40 mesh sieve, mixed homogeneously, and then weighed. Vitamin A standard solution (30 $\mu \mathrm{g} / \mathrm{mL}$ retinol), vitamin E standard solution ( $350 \mu \mathrm{g} / \mathrm{mL} \alpha$-tocopheryl acetate), and approximately $3 \mathrm{~g}$ of samples were added separately to amber Erlenmeyer flasks equipped with a reflux condenser and a nitrogen inlet, after which $95 \%$ ethanol was added and the Erlenmeyer flask swept with nitrogen and heated to a reflux temperatures $\left(\sim 78.1^{\circ} \mathrm{C}\right)$. Two milliliters of aqueous potassium peroxide at concentration $0.5 \mathrm{~g} / \mathrm{mL}$ was added to each sample. The samples were then refluxed for $45 \mathrm{~min}$ and cooled to room temperature, after which potassium peroxide was neutralized with the addition of acetic acid in acetonitrile through swirling. The solutions were diluted to $100 \mathrm{~mL}$ with acetonitrile, and filtered through $0.45 \mu \mathrm{m}$ filters. The samples and standards were determined by reversed-phase HPLC, and comparison of the peak areas of the samples versus the peak areas of the standards were used for quantifications of vitamin A and E.

\section{Vitamin C (ascorbic acid)}

Vitamin $\mathrm{C}$ contents in the sea cucumber whole body and body wall were determined according to compendium of methods for food analysis [15]. In short, freeze-dried samples were cut into 
small pieces and then homogenized as finely as possible. The samples were weighed and $2.5 \mathrm{~g}$ dissolved with $3 \%$ meta-phosphoric acid in separate $100 \mathrm{~mL}$ volumetric flasks. The solutions were shaken vigorously for $2 \mathrm{~min}$, sonicated for $5 \mathrm{~min}$, and made up to $100 \mathrm{~mL}$ with $3 \% \mathrm{~m}$ phosphoric acid. They were filtered through $0.45 \mu \mathrm{m}$ membrane filters and analyzed for vitamin $C$ by a reversed-phase HPLC. In each analysis, approximately $20 \mu \mathrm{l}$ of ascorbic acid of a standard solution and $20 \mu \mathrm{l}$ of each sample was injected into a HPLC column, with the quantification of vitamin $\mathrm{C}$ being determined by comparison of the peak with the retention time and peak area of the ascorbic acid standard.

\section{RESULTS}

\section{Proximate composition}

The proximate compositions of freeze-dried H. scabra whole body and body wall are shown in table 1 . The whole body of H. scabra, sample contained $79.65 \%$ moisture, $22.50 \%$ protein, $1.55 \%$ lipid, $61.98 \%$ ash, and $7.71 \%$ carbohydrate (dry base). The body wall of $H$. scabra contained $12.13 \%$ moisture, $55.18 \%$ protein, $1.02 \%$ lipid, $27.97 \%$ ash, and $3.70 \%$ carbohydrate (dry base).

Table 1. Proximate composition of the sea cucumber, Holothuria scabra.

\begin{tabular}{|l|c|c|}
\hline \multirow{2}{*}{ Component } & \multicolumn{2}{|c|}{ Gram per 100 g tissue (dry weight) } \\
\cline { 2 - 3 } & Whole body & Body wall \\
\hline Moisture & 6.25 & 12.13 \\
\hline Protein & 22.50 & 55.18 \\
\hline Lipid & 1.55 & 1.02 \\
\hline Ash & 61.98 & 27.97 \\
\hline Carbohydrate & 7.71 & 3.70 \\
\hline
\end{tabular}

\section{Amino acid composition}

The compositions of total amino acids of $H$. scabra whole body and body wall are shown in Figure 1A. Eighteen amino acids were detected, including 9 essential amino acids and 9 nonessential amino acids, and 2 major amino acids of collagen, namely hydroxyproline and hydroxylysine. In the following order, the three most abundant amino acids found in both whole body and body wall were glycine $(34.11 \mathrm{mg} / \mathrm{g}$ and $79.65 \mathrm{mg} / \mathrm{g}$ dry weight respectively), glutamic acid $(31.91 \mathrm{mg} / \mathrm{g}$ and $67.64 \mathrm{mg} / \mathrm{g}$ dry weight respectively), and proline $(22.34 \mathrm{mg} / \mathrm{g}$ and $44.52 \mathrm{mg} / \mathrm{g}$ dry weight respectively). Free amino acids in $H$. scabra whole body and body wall are shown in Figure 1B. Three of the major free amino acids found in whole body and body wall included glutamic acid, arginine, and aspartic acid, of which glutamic acid levels were the highest at $1.92 \mathrm{mg} / \mathrm{g}$ and $1.22 \mathrm{mg} / \mathrm{g}$ dry weight respectively. 

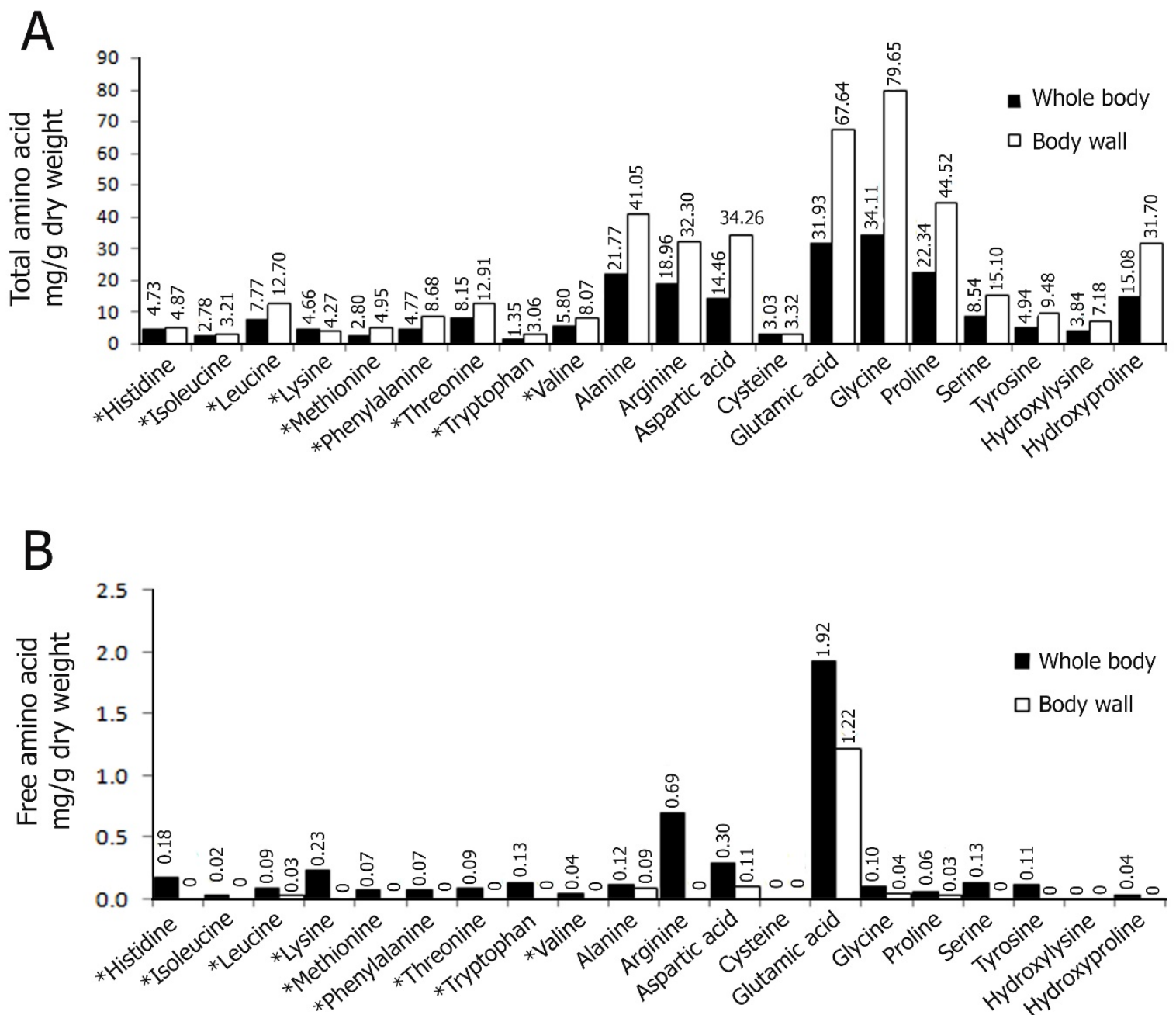

Figure 1. Total (A) and free amino acids (B) of freeze-dried H. scabra whole body and body wall (milligram per gram of dry weight). *, essential amino acids.

\section{Fatty acid composition}

The fatty acid compositions of the whole body and body wall of $H$. scabra are shown in Table 2. The main fatty acids found in the whole body were C18:0, C24:1, and C18:1, while those found in the body wall were C20:4, C18:0, and C24:1. High levels of stearic acid (C18:0), a direct precursor of the oleic acid, were found in the whole body at $2.12 \mathrm{mg} / \mathrm{g}$ dry weight and in the body wall at $1.50 \mathrm{mg} / \mathrm{g}$ dry weight. Other fatty acids important for the growth and development of humans were also found in H. scabra. Nervonic acid (NA, C24:1) is present at high levels with $1.71 \mathrm{mg} / \mathrm{g}$ in the whole body and $1.44 \mathrm{mg} / \mathrm{g}$ in the body wall. Linoleic acid (LA), an essential omega- 6 fatty acid, was found in the whole body of the sea cucumber $H$. scabra at $5.46 \%$ and in the body wall at 3.37\%. Alpha-linolenic acid (ALA), an essential omega-3 fatty acid, is a precursor of longer-chain unsaturated n-3 fatty acids, including EPA and DHA. ALA was detected in the whole body at $1.13 \%$ and body wall at $0.82 \%$. Arachidonic acid (ARA), an omega-6 polyunsaturated fatty acid, was found in whole body at $3.63 \%$ and found at a very high level in the body wall at $28.42 \%$. Eicosapentaenoic acid (EPA) was found in the whole body at $1.13 \%$ and in body wall at $6.57 \%$. 
Table 2. Fatty acid composition of freeze-dried Holothuria scabra whole body and body wall (milligram per gram of dry weight). Asterisks indicate the fatty acids that have been shown to be important for growth and development of humans. N/D; not detected.

\begin{tabular}{|c|c|c|c|c|}
\hline \multirow[b]{2}{*}{ Fatty acid } & \multicolumn{2}{|c|}{ Whole body } & \multicolumn{2}{|c|}{ Body wall } \\
\hline & $\%$ weight & $\begin{array}{c}\mathrm{mg} / \mathrm{g} \text { dry } \\
\text { weight }\end{array}$ & $\%$ weight & $\begin{array}{l}\text { mg/g dry } \\
\text { weight }\end{array}$ \\
\hline C14:0 & 0.71 & 0.10 & 1.22 & 0.20 \\
\hline C15:0 & 0.44 & 0.06 & 0.86 & 0.14 \\
\hline C16:0 & 9.15 & 1.23 & 6.05 & 1.00 \\
\hline C17:0 & 1.24 & 0.17 & 1.29 & 0.21 \\
\hline $\mathrm{C} 18: 0 *$ & 15.80 & 2.12 & 9.01 & 1.50 \\
\hline C20:0 & 7.00 & 0.94 & 5.04 & 0.84 \\
\hline $\mathrm{C} 21: 0$ & 6.26 & 0.84 & 4.37 & 0.73 \\
\hline $\mathrm{C} 22: 0$ & 6.89 & 0.92 & 4.90 & 0.81 \\
\hline $\mathrm{C} 23: 0$ & 2.70 & 0.36 & 2.00 & 0.33 \\
\hline $\mathrm{C} 24: 0$ & 1.00 & 0.13 & 2.66 & 0.44 \\
\hline ¿Saturated fatty acid & 51.19 & 6.87 & 37.39 & 6.20 \\
\hline $\bar{C} 14: 1$ & $\mathrm{~N} / \mathrm{D}$ & $\mathrm{N} / \mathrm{D}$ & $\mathrm{N} / \mathrm{D}$ & N/D \\
\hline C15:1n-10 & $\mathrm{N} / \mathrm{D}$ & $\mathrm{N} / \mathrm{D}$ & $\mathrm{N} / \mathrm{D}$ & N/D \\
\hline C16:1n-7 & 2.40 & 0.32 & 1.86 & 0.31 \\
\hline C17:1n-10 & $\mathrm{N} / \mathrm{D}$ & $\mathrm{N} / \mathrm{D}$ & N/D & N/D \\
\hline C18:1n-9t & 0.86 & 0.11 & 0.48 & 0.08 \\
\hline $\mathrm{C} 18: 1 \mathrm{n}-9 \mathrm{c} *$ & 11.93 & 1.60 & 6.32 & 1.05 \\
\hline C20:1n-11c & 3.82 & 0.51 & 1.79 & 0.30 \\
\hline $\mathrm{C} 22: 1 \mathrm{n}-9$ & 2.69 & 0.36 & 0.92 & 0.15 \\
\hline $\mathrm{C} 24: 1 \mathrm{n}-9 *$ & 12.76 & 1.71 & 8.69 & 1.44 \\
\hline ¿Monounsaturated fatty acid & 34.46 & 4.61 & 20.06 & 3.33 \\
\hline C18:2n-6t & $\mathrm{N} / \mathrm{D}$ & $\mathrm{N} / \mathrm{D}$ & $\mathrm{N} / \mathrm{D}$ & N/D \\
\hline $\mathrm{C} 18: 2 \mathrm{n}-6 \mathrm{c} *$ & 5.46 & 0.73 & 3.37 & 0.56 \\
\hline C18:3n-6 & $\mathrm{N} / \mathrm{D}$ & $\mathrm{N} / \mathrm{D}$ & N/D & $\mathrm{N} / \mathrm{D}$ \\
\hline $18: 3 n-3 *$ & 1.13 & 0.15 & 0.82 & 0.14 \\
\hline $\mathrm{C} 20: 2$ & 3.01 & 0.40 & 2.46 & 0.41 \\
\hline$C 20: 3 n-6$ & $\mathrm{~N} / \mathrm{D}$ & $\mathrm{N} / \mathrm{D}$ & N/D & $\mathrm{N} / \mathrm{D}$ \\
\hline$C 20: 3 n-3$ & $\mathrm{~N} / \mathrm{D}$ & $\mathrm{N} / \mathrm{D}$ & $\mathrm{N} / \mathrm{D}$ & $\mathrm{N} / \mathrm{D}$ \\
\hline$C 20: 4 n-6 *$ & 3.63 & 0.49 & 28.42 & 4.72 \\
\hline $\mathrm{C} 22: 2$ & $\mathrm{~N} / \mathrm{D}$ & $\mathrm{N} / \mathrm{D}$ & N/D & $\mathrm{N} / \mathrm{D}$ \\
\hline$C 20: 5 n-3 *$ & 1.13 & 0.15 & 6.57 & 1.09 \\
\hline$C 22: 6 n-3$ & $\mathrm{~N} / \mathrm{D}$ & $\mathrm{N} / \mathrm{D}$ & 0.44 & 0.07 \\
\hline ¿Polyunsaturated fatty acid & 14.36 & 1.92 & 42.56 & 7.07 \\
\hline SOmega-3 & 2.26 & 0.3 & 8.31 & 1.38 \\
\hline EOmega-6 & 9.09 & 1.22 & 31.78 & 5.28 \\
\hline SOmega-9 & 28.23 & 3.78 & 16.41 & 2.72 \\
\hline
\end{tabular}

\section{Collagen content}

The collagen compositions of the whole body and body wall of $H$. scabra were $15.07 \mathrm{~g} / 100 \mathrm{~g}$ and $18.38 \mathrm{~g} / 100 \mathrm{~g}$ dry weight respectively. The yields of collagen from both the whole body and body wall of $H$. scabra are higher than that in cartilage of the blacktip shark, cartilage from brownbanded bamboo shark, and chicken feet (Figure 2). 


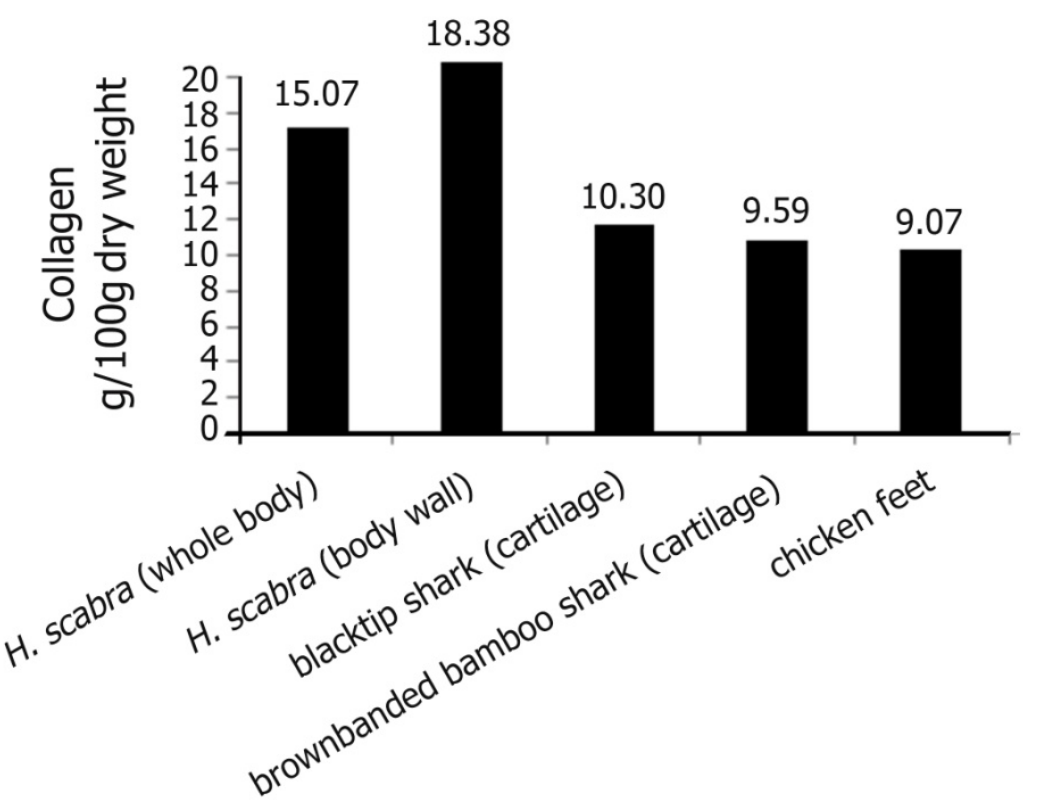

Figure 2. Comparison of collagen content from H. scabra whole body and body wall with cartilage of blacktip, and brownbanded bamboo sharks, and chicken feet.

\section{GABA content}

The GABA content in the H. scabra whole body was $4.67 \mathrm{mg} / \mathrm{kg}$ dry weight, which was not found in the body wall. The content of GABA in the sea cucumber was much lower than that in germ rice as shown in Figure 3.

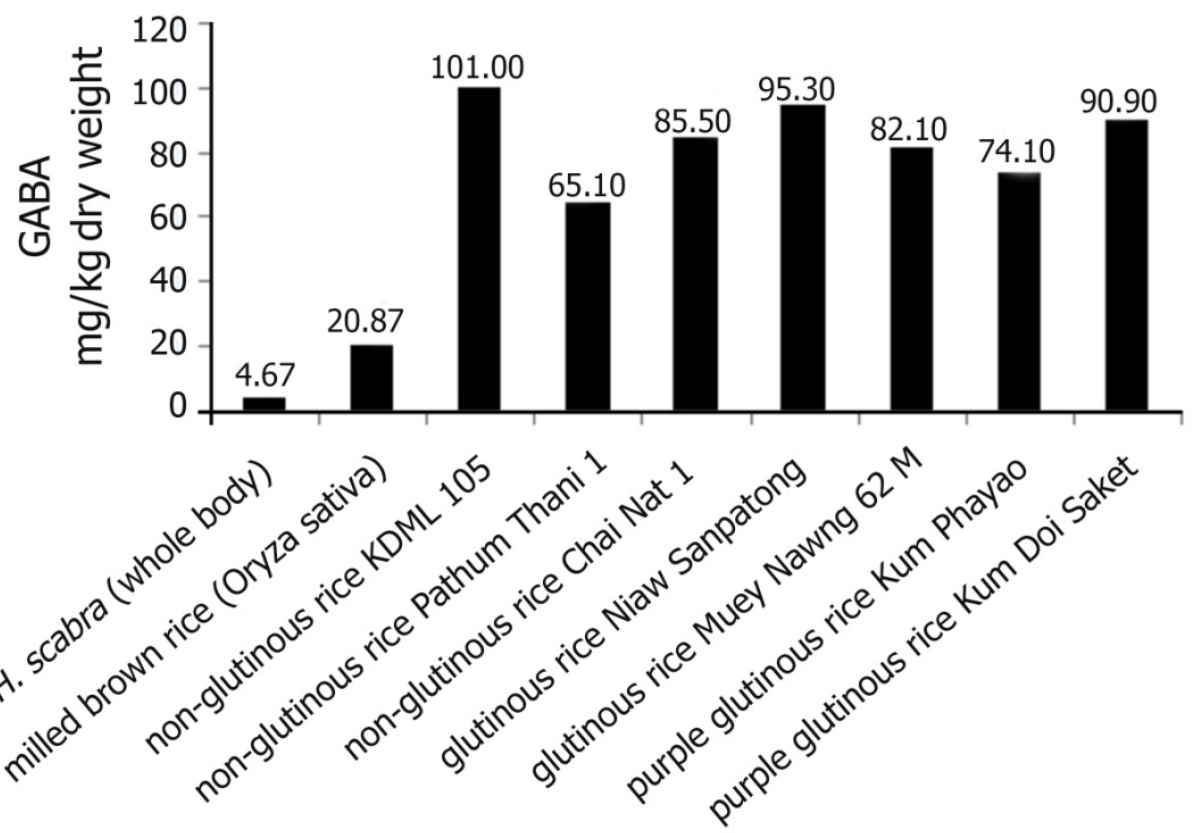

Figure 3. Comparison of GABA from H. scabra whole body with brown, non-glutinous, glutinous, and purple glutinous rice.

\section{Vitamin A (retinol)}

Vitamin A was not detected in the H. scabra whole body and body wall. 


\section{Vitamin C (ascorbic acid)}

Vitamin C content in the H. scabra whole body was $3.19 \mathrm{mg} / 100 \mathrm{~g}$, and in the body wall was $1.32 \mathrm{mg} / 100 \mathrm{~g}$ dry weight. The content of vitamin $\mathrm{C}$ in the $H$. scabra was much lower than in fruits as shown in Figure 4A.

\section{Vitamin E ( $\alpha$-tocopherol)}

Vitamin E content in the whole body was $2.82 \mathrm{mg} / 100 \mathrm{~g}$, and in the body wall was $4.94 \mathrm{mg} / 100$ $\mathrm{g}$ dry weight. The content of vitamin $\mathrm{E}$ in the sea cucumber was lower than that in oil from seeds and fishes as shown in Figure 4B.

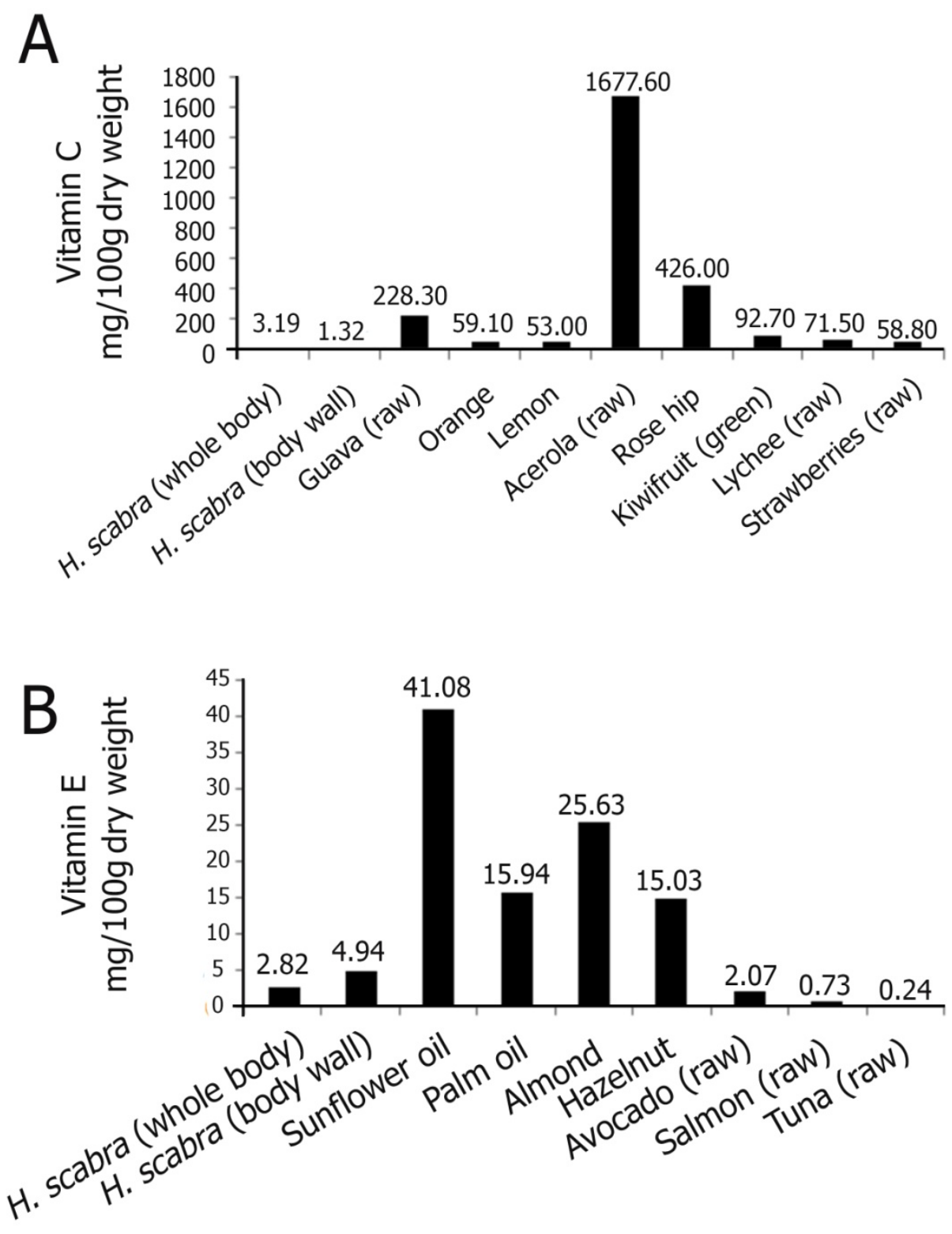

Figure 4. (A) Comparison of vitamin $\mathrm{C}$ from H. scabra whole body and body wall with fruits. (B) Comparison of vitamin E from H. scabra whole body and body wall with sunflower oil, palm oil, almond seed, hazelnut seed, avocado flesh, salmon flesh, and tuna.

\section{DISCUSSION}

The major contents of H. scabra are similar to those reported in dried S. herrmanni, Thelenota ananas, H. fuscogilva, H. fuscopunctata, Actinopyga mauritiana, and Bohadschia argus [2]. 
The main characteristics are the high quantity of protein, very low amounts of lipid, and the high quantity of ash which may be the result from the minerals deposit in the body wall of a sea cucumber.

According to amino acid composition, we expected high levels of glycine and proline, and the presence of hydroxyproline and hydroxylysine, as they reflected the high collagen content in the sea cucumber. Glycine and glutamic acid were also dominant amino acids in other sea cucumbers, including S. herrmanni, Thelenota ananas, H. fuscogilva, H. fuscopunctata, Actinopyga mauritiana, and Bohadschia argus [3], Cucumaria frondosa [8], and A. japanicus [2]. A high amount of proline was found only in H. scabra, particularly within the body wall. The essential amino acids, leucine, threonine, phenylalanine, and valine, were present at levels higher than others in the total amino acid analysis but not in the free amino acid analysis. This may reflect specific incorporation into structural proteins. Additionally, semi-essential amino acids, such as arginine and tyrosine, required for human infant and child growth [23], were detected at moderate levels in both whole body and body wall. Moreover, several studies have reported that a low lysine to arginine ratio could reduce levels of plasma cholesterol [24, 25]. In H. scabra, the ratio of lysine to arginine in the whole body was 0.25 and in the body wall was 0.13 ; moreover, these were consistent with those of other sea cucumbers, including $S$. herrmanni (0.27), T. ananas (0.39), T. anax (0.33), H. fuscogilva (0.13), H. fuscopunctata (0.15), A. mauritiana (0.25), A. caerulea (0.21), B. argus (0.36) [3], and A. japanicus (0.62) [2]. Interestingly, the ratios of lysine: arginine in $H$. scabra are lower than that in varieties of fish, including European seabass Dicentrarchus labrax (0.85), gilthead seabream Sparus aurata (0.86), and turbot Psetta maxima (0.95) [19]. Therefore, the results of the present study and previous reports indicated that a sea cucumber is a healthy food that can help to reduce hypercholesterolemia.

Amino acids, especially free amino acids, are the main contributors of the taste and flavor of foods. For example, free amino acids can give sweet, bitter, sour, sulfurous, and umami flavors [20]. Glutamic acid, particularly L-glutamic acid, plays important roles in the taste and palatability of foods [21], so the high level of glutamic acid in the sea cucumber probably enhances its taste. Furthermore, glutamate acts as an excitatory neurotransmitter in the central and peripheral nervous systems of mammals [22], which is the precursor in the syntheses of proteins, peptides, and glutathione, a natural antioxidant molecule [23]. Moreover, the neurotransmitter glutamate plays an important role in learning and memory in hippocampus by action through N-methyl-D-Aspartate receptors (NMDAR) [24].

The major fatty acid found in H. scabra was stearic acid. Unlike other saturated fatty acids, stearic acid does not raise blood total cholesterol and low density lipoprotein (LDL) cholesterol levels. In humans, a diet containing high stearic acid lowers LDL cholesterol and triglyceride while increasing HDL cholesterol more than a diet containing high trans fatty acid [25]. The second most abundant fatty acid found in whole body of $H$. scabra was NA. NA is found in sphingolipids, such as sphingomyelin in the myelin sheath of nerve fibers and in the white matter of animal brains [26]. NA was also found in other sea cucumbers at a much lower amount than in H. scabra, and was not detected in fishes [27, 28]. NA supplementation is thought to improve neurological function [29] and enhance myelination in patients with demyelinating disease [30]. Martinez and Mougan [30] revealed that the predominant myelin monounsaturated fatty acid in human brain is NA, which increases very rapidly after birth until children are eight years old. Therefore, a low intake and decrease in NA could affect myelination. Our novel finding of the high level of NA in H. scabra indicated a major 
neurological benefit of eating sea cucumbers. LA, ALA, ARA, and EPA levels in H. scabra were compared with other sea cucumbers and fishes. LA has also been detected at high levels in other sea cucumber, S. chloronotus (12.87\%), and the Nile tilapia, Oreochromis niloticus (20.90\%) [27]. The levels of ALA found in whole body and body wall of $H$. scabra were low and found very low in other sea cucumbers at $0-1.88 \%[3,5]$, and fishes at $0-1.86 \%[27,28]$. ARA found in $H$. scabra was detected at the highest level among sea cucumbers and fishes. ARA is derived as an intermediate from diacylglycerol by the action of phospholipase- $\mathrm{A}_{2}$ and then transformed to eicanosoids, including prostaglandins and leukotrienes, which are key antiinflammatory factors [30]. EPA in H. scabra is much lower than that found in other sea cucumbers, including C. frondosa (52.00\%) [8] and S. chloronotus [5]. EPA is also found in fishes at $1.88 \%-7.08 \%$ [28]. Docosahexaenoic acid (DHA) was not found in the whole body and body wall of $H$. scabra, but was found in other sea cucumbers at $1.20 \%-57.55 \%[5,8]$ and in fishes at $1.07 \%-28.30 \%[27,28]$. The wide range of EPA and DHA in various animals may be due to the different methods of extractions, or they have different contents as a result of diet and endogenous factors. Significantly, we found that $H$. scabra contains the highest levels of ARA and NA when compared with other sea cucumbers and fishes.

The yields of collagen from both the whole body and body wall of $H$. scabra are higher than that in the cartilage of the blacktip shark, cartilage from brownbanded bamboo shark, and chicken feet [32-34]. Zhao et al. [33] reported that gelatin from collagen of the sea cucumber, Acaudina molpadioidea, had the ability to inhibit angiotensin-I-converting enzyme (ACE), which plays an important physiological role in regulating blood pressure. The collagen from the body wall of sea cucumber was used as a nutrient supplement in anemic patients for enhancing hemotogenesis and arthritis patients for reducing pain [1].

The content of GABA in the sea cucumber was much lower than that in germ rice $[13,35]$ as shown in Figure 3. Nevertheless, the small amount of GABA was consistent with the anatomical structure of the sea cucumber that has small radial nerves, which contain GABA.

Vitamin A was not detected in the H. scabra. The content of vitamin C in the H. scabra was much lower than in fruits, including guava, orange, lemon, acerola, rose hip, kiwifruit, lychee, and strawberries [36]. The content of vitamin E in the sea cucumber was lower than that in sunflower oil, palm oil, almonds, and hazelnuts but higher than in avocado, salmon, and tuna [36].

\section{CONCLUSIONS}

In conclusion, the sea cucumber, H. scabra, contained high quantities of protein, especially collagen and very low lipid. It had high levels of essential amino acids, essential fatty acids especially NA and ARA, which also contained GABA, vitamin C, and vitamin E. Thus, this sea cucumber has the potential to be an effective functional food, due to its high nutritional values.

List of Abbreviation: GABA - gamma aminobutyric acid; AOAC - Association of Official Analytical Chemists; NA - Nervonic acid; LA - Linoleic acid; ALA - Alpha-linolenic acid; ARA - Arachidonic acid; EPA - Eicosapentaenoic acid; DHA - Docosahexaenoic acid

Competing Interests: All authors have no competing of interest.

Author's Contributions: All authors contributed to this study. 
Acknowledgments and Funding: This research was supported by The Agricultural Research Development Agency (Public Organization) and Mahidol University.

\section{REFERENCES:}

1. Kiew PL, Don MM. Jewel of the seabed: sea cucumbers as nutritional and drugcandidates. Int J Food Sci Nutr 2012, 63:616-636.

2. Yang H, Hamel JF, Mercier A, eds. The sea cucumber Apostichopus japonicus:history, biology and aquaculture. Academic Press 2015, 39:1-478.

3. Wen J, Hu C, Fan S. Chemical composition and nutritional quality of sea cucumbers.J Sci Food Agr 2010, 90:2469-2474.

4. Abdul Aziz C, Wagiman M, Hasan S. The analgesic effects of intraperitonealadministration of holothuria extracts on formalin-induced pain. Biomedicine International 2011, 2:12-15.

5. Fredalina BD, Ridzwan BH, Abidin AA, Kaswandi MA, Zaiton H, Zali I, KittakoopP, Jais AM. Fatty acid compositions in local sea cucumber, Stichopus chloronotus, for wound healing. Gen Pharmacol 1999, 33:337-340.

6. Zohdi RM, Zakaria ZA, Yusof N, Mustapha NM, Abdullah MN. Sea cucumber(Stichopus hermanii) based hydrogel to treat burn wounds in rats. J Biomed MaterRes 2011, 98:30-37.

7. Zou ZR, Yi YH, Wu HM, Wu JH, Liaw CC, Lee KH. Intercedensides A-C, three newcytotoxic triterpene glycosides from the sea cucumber Mensamaria intercedensLampert. J Nat Prod 2003, 66:1055-1060.

8. Zhong Y, Khan MA, Shahidi F. Compositional characteristics and antioxidantproperties of fresh and processed sea cucumber (Cucumaria frondosa). J Agric Food Chem 2007, 55: 1188-1192.

9. Collin P. Tissue fraction of sea cucumber for the treatment of inflammation. USPatent $5,770,205$ (1998)

10. Althunibat O, Ridzwan B, Taher M, Jamaludin M, Ikeda M, Zali B. In vitro antioxidant and antiproliferative activities of three Malaysian sea cucumber species.Eur J Sci Res 2009, 37: 376-387.

11. Preston G. Inshore marine resources of the South Pacific: Their biology andmanagement, chapter 11, South Pacific Forum Fisheries Agency, Honiara, Solomon Islands 1994, 371-407.

12. AOAC. Official Method of Analysis of AOAC Intl. 17th ed. Method 950.46, 981.10,922.06, 920.153, 996.06, and 990.26 Association of Official Analytical Chemists, Washington, DC, USA

13. Iwaki K, Kitada Y. Availability of partially milled rice as a daily source of $\gamma$ aminobutyric acid. Food Sci Technol 2007, 13:41-44.

14. DeVries J, Egberg D, Heroff J. Concurrent analysis of vitamin A and vitamin E byreversed phase high performance liquid chromatography. Liquid chromatographicanalysis of food and beverages 1979, 2: 477-497.

15. Compendium of methods for food analysis. 2003, 112-114.

16. Imura K, Okada A. Amino acid metabolism in pediatric patients. Nutrition 1998,14:143-148. 
17. Gudbrandsen OA, Wergedahl H, Liaset B, Espe M, Berge RK. Dietary proteins withhigh isoflavone content or low methionine-glycine and lysine-arginine ratios arehypocholesterolaemic and lower the plasma homocysteine level in male Zucker fa/fa rats. Br J Nutr 2005, 94: 321-330.

18. Rajamohan T, Kurup PA. Lysine: arginine ratio of a protein influences cholesterolJ Exp Biol 1997, 35: 1218-1223.

19. Kaushik S. Whole body amino acid composition of European seabass (Dicentrarchuslabrax), gilthead seabream (Sparus aurata) and turbot (Psetta maxima) with an estimation of their IAA requirement profiles. Aquat Living Resour 1998, 11:355-358.

20. Kawai M, Okiyama A, Ueda Y. Taste enhancements between various amino acids and IMP. Chemical senses 2002, 27:739-745.

21. Faurion A. Are umami taste receptor sites structurally related to glutamate CNS receptor sites? Physiol Behav 1991, 49: 905-912.

22. Kung L-H, Gong K, Adedoyin M, Ng J, Bhargava A, Ohara PT, Jasmin L. Evidence for glutamate as a neuroglial transmitter within sensory ganglia. PloS ONE 2013, 8:e68312.

23. Fonnum F. Glutamate: a neurotransmitter in mammalian brain. J Neurochem 1984, 42: $1-11$.

24. Kravitz E, Gaisler-Salomon I, Biegon A. Hippocampal glutamate NMDA receptor loss tracks progression in Alzheimer's disease: quantitative autoradiography in postmortem human brain. PLoS ONE 2013, 8:e81244.

25. Aro A, Jauhiainen M, Partanen R, Salminen I, Mutanen M. Stearic acid, trans fatty acids, and dairy fat: effects on serum and lipoprotein lipids, apolipoproteins, lipoprotein(a), and lipid transfer proteins in healthy subjects. Am J Clin Nutr 1997, 65:1419-1426.

26. Babin F, Sarda P, Limasset B, Descomps B, Rieu D, Mendy F, Crastes de Paulet A. Nervonic acid in red blood cell sphingomyelin in premature infants: an index of myelin maturation? Lipids 1993, 28:627-630.

27. Abou Y, Fiogbé E, Beckers Y, Micha J. Approximate compositional values and tissue fatty acid profiles of Nile tilapia (Oreochromis niloticus L.) fed Azolla-diets in earthen ponds. Scientific Research 2011, 2: 964-973.

28. İbrahim Haliloğlu H, Abdulkadir Bayır A, Necdet Sirkecioğlu A, Mevlüt Aras N, Muhammed A. Comparison of fatty acid composition in some tissues of rainbow trout (Oncorhynchus mykiss) living in seawater and freshwater. Food Chem 2004, 86: 5559.

29. Taylor D. New very long chain fatty acid seed oils produced through introduction of strategic genes into Brassica carinata. Inform AOCS 2010.

30. Martinez M, Mougan I. Fatty acid composition of human brain phospholipids during normal development. J Neurochem 1998, 71: 2528-2533.

31. Yao JK, van Kammen DP. Membrane phospholipids and cytokine interaction in schizophrenia. Int Rev Neurobiol 2004, 59: 297-326.

32. Kittiphattanabawon P, Benjakul S, Visessanguan W, Shahidi F. Isolation and characterization of collagen from the cartilages of brownbanded bamboo shark and blacktip shark. LWT - Food Sci Technol 2010, 5:792-800. 
33. Zhao Y, Li B, Liu Z, Dong S, Zhao X, Zeng M. Antihypertensive effect and purification of an ACE inhibitory peptide from sea cucumber gelatin hydrolysate. Process Biochem 2007, 42:1586-1591.

34. Liu D, Lin Y, Chen M. Optimum condition of extracting collagen from chicken feet and its characteristics. Asian-Australasian Journal of Animal Sciences 2001, 14:16381644.

35. Karladee D, Suriyong S. $\gamma$-Aminobutyric acid (GABA) content in different varieties of brown rice during germination. Science Asia 2012, 38:13-7.

36. U.S. Department of Agriculture ARS. USDA National Nutrient Database for Standard Reference, Release 27. Available from: http://www.ars.usda.gov/ba/bhnrc/ndl. Accessed 2014. 